\title{
A Paisagem, Espelho de uma Civilização
}

\author{
PierRe Monbeig
}

Em uma das conferências que em 1938 acompanharam o clássico Salão de Maio, um de meus colegas teve a extrema gentileza de preparar, indiretamente, o começo desta conferência: tratava-se dos impressionistas franceses do século XIX e dos paisagistas holandeses do século XVII, e o meu eminente colega expunha, com engenho, que a arte dos segundos parecia-lhe mais completa do que a técnica dos primeiros, não por motivos puramente estéticos mas porque as paisagens de Ruysdael e Ver Meer de Delft exprimem também a civilização dos Países-Baixos naquele século; volumes e cores são reflexos da vida econômica e social neerlandesa nas proximidades de 1650 e o amarelo da parede de Bergotte seria como que a expressão pictórica do ouro de Amsterdam. Reconheço bem a minha ousadia em passear os meus pesados tamancos de geógrafo nos delicados jardins da pintura; apossando-me, entretanto, da idéia expressa no Salão de Maio, surge-me naturalmente uma pergunta: por que, na mesma época, enquanto Poussin coloria paisagens que são apenas belas, seus contemporâneos dos Países Baixos pintavam paisagens pátrias, exprimindo ao mesmo tempo, toda a civilização delas. Será porque os campos holanmdeses com seus moinhos de vento, seus canais onde deslizam navios chegados do fim do mundo, têm virtude especial?

A história e o método de trabalho do historiador de hoje podem levar-nos a uma explicação: para julgar-se uma obra humana é necessário recolocá-la no seu meio histórico e, da mesma maneira pela qual os historiadores da Reforma procuram compreender o que a obra de Erasmo representava para seu tempo, o que lhe per-

\footnotetext{
* Conferência de Extensão Universitária da Faculdade de Filosofia, Ciências e Letras, da Universidade de São Paulo, realizada em 1 de setembro de 1939, publicada originalmente em Ensaios de Geografia Humana, Livraria Martins, 1940.
} 
tencia em seus escritos e o que pertencia aos leitores, da mesma maneira devemos procurar aquilo que os pintores holandeses viam nas paisagens de sua terra no século XVII e o que os eventuais compradores de suas telas queriam encontrar nelas.

Ora, ninguém ignora que, nesse século, a Holanda estava no período áureo: vindos do Brasil e da Insulíndia, galeões lhes traziam as riquezas de um mundo novo; suas frotas e seus bancos são os senhores do mundo e o dinheiro aflue para os burgueses de Leyde, de Utrecht, de Amsterdam e de Delft. E com ele os holandeses combatem seu eterno inimigo: a água. É então que os engenheiros estabelecem os sistemas de drenagem dos pântanos do Reno e do Mosa, é então que são aperfeiçoados os moinhos de vento destinados a bombear a água. Esta é aprisionada pelos diques, no lugar dos pântanos surge a terra mais fértil do mundo, terra feita de sangue, de carne, de suor humano. Em suma, desaparece a paisagem natural dos Países-Baixos e o homem constrói outra, verdadeiro reflexo da técnica, da riqueza, da civilização holandesa. E Ruysdael, Ver Meer, Rembrandt participam em suas estampas do orgulho nacional, e glorificam esta luta contra as águas. Eles fazem o que trezentos anos mais tarde fará um Manet, no século da estrada de ferro, pintando a Estação de São Lázaro. Mais ainda: a paisagem que eles devem representar está rarejante de uma civilização ainda recente. A paisagem é-lhes tão pouco familiar quanto o arranha-céu e a arquitetura moderna para o pintor brasileiro; não é de admirar, portanto, que suas telas sejam também transbordantes de civilização. Elas constituem ao mesmo tempo documentação geográfica, pois mostram em essência a ação do homem sobre a paisagem natural.

No entanto, fato curioso, há relativamente pouco tempo que se dá toda a devida atenção à ação das sociedades humanas sobre a natureza: a transformação da paisagem natural pelo homem conservou-se insuspeitada ou, pelo menos, apenas indicada nas zonas de civilização antiga, até o grande movimento de renascimento da geografia moderna. Foi necessário esperar muito tempo ainda depois da renovação dos estudos geográficos no século passado, para ver-se o geógrafo atraído pelos estudos da paisagem.

Com efeito, nos meados do século XIX, com Ritter e depois com Ratzel sabe-se que as concepções das relações do homem e do meio natural eram singularmente simples: é o período do determinismo geográfico, segundo o qual as relações "homem-meio natural" têm um sentido único, como as ruas entulhadas de nossas cidades: a natureza possuía, no espírito dos geógrafos de então, alguma coisa do bom tirano, do déspota esclarecido; as regiões calcárias eram necessariamente centros de povoamento agrupados e regiões pobres, de criação; em contraste, os terrenos impermeáveis, as ricas aluviões das margens dos rios, por exemplo, trariam obrigatoriamente a dispersão dos homens, pastagens boas e colheitas abundantes. E todas as ações dos homens em relação ao meio se desenvolviam num quadro geográfico facilmente demarcado: a região natural. Compreendia-se assim, sem dificuldade, que os gêneros de vida montanheses se desenvolvessem e prosperassem no vale alto dos Alpes ou dos Andes; que a zona situada entre os isotermas e 
isoietas $\mathrm{x}$ e $\mathrm{v}$ encerrava a mesma atividade humana e correspondia exatamente a certo tipo de casa. A região natural constituía inexoravelmente a base territorial dos gêneros de vida.

Mas esta concepção geográfica, que tem qualquer coisa de tragédia clássica pela preocupação da unidade, foi logo desmentida pelos fatos; à medida que os geógrafos amontoavam, nas prateleiras das bibliotecas, monografias preciosas e eruditas, eles eram levados a constatar que o determinismo falhava muitas vezes, que os fatos desmentiam as teorias. Ao lado das forças naturais como a chuva, o vento, o mar, o vulcão, aparece outra força natural, o homem. O homem, que, com seus utensílios, a inteligência que lhe guia as mãos, é capaz de transformar a tal ponto o meio natural que, aquilo que tomamos atualmente por uma paisagem obra da natureza, não é senão o cenário construído por ele. Tornava-se cada dia mais evidente que a ação geográfica dos homens se exercia como se exerce o talento do arquiteto urbanista, que transforma o ingrato arrabalde industrial urbano em juma seqüência de parques verdejantes, como o arquiteto desenhista de jardins cria uma paisagem amável no lugar onde se erguia uma floresta frondosa. A ação dos homens sobre a paisagem natural foi então comparada à de jardineiro tal modo familiarizado com o espetáculo que tem sob os olhos que chega a esquecer o quadro natural. Assim, os parisienses que vão da Avenida da Ópera ao Banco de França ali vizinho, não suspeitam que atravessam um antigo meandro do Sena o qual, entretanto, subsistiu bastante tempo e os grupos de rapazes e moças que passeiam pela Avenida Paulista nem de leve pensam que seus avós poderiam caçar ali há algumas dezenas de anos.

Em suma, com uma bela probidade científica - porque foi este exatamente o caso do mestra da moderna geografia humana, Vidal de La Blache - os geógrafos confessaram "mea culpa": reconheceram que o sentido único do determinismo geográfico era infinitamente mais complexo do que haviam pensado. E o quadro da região natural pareceu muito estreito: por certo, muitas vezes a extensão de uma determinada paisagem corresponde com precisão à extensão de uma curva térmica ou pluviométrica, ou ainda pára exatamente num contato geológico. Entretanto, o mais das vezes, a paisagem se superpõe a duas ou mais regiões naturais e convém fazer uma classificação dos tipos e sub-tipos de paisagem depois de compará-la à classificação que nos dão os morfologistas, os climatologistas e os botânicos. Trata-se, em todo o caso, de uma paisagem cultural, substituída pelos homens à paisagem natural; o grupo humano apodera-se sempre do meio, quer vindo a dominá-lo, quer preferindo adaptar-se a ele, o que constitui ainda uma maneira de vencê-lo. Mas, como a cultura de um grupo evolui, sua paisagem também evolui: o mesmo suporte natural viu sucederem-se paisagens diferentes, sendo cada uma o reflexo da civilização do grupo de dado momento de sua história. Assim a paisagem não é mais considerada como produto da geologia e do clima, mas como o reflexo da técnica agrícola ou industrial, da estrutura econômica ou social, e mesmo, se se pensa no Partenon, nas catedrais e nos estádios modernos, da psicologia do grupo humano. Normalmente a geografia de Vidal de la Blache e dos seus alunos encontrava pro- 
longamento na história, reveladora das transformações da paisagem, mergulhando suas raízes mais profundas na pré-história tão rica de ensinamentos.

São sobretudo os estudos acumulados nos países da Europa Ocidental que encaminharam os geógrafos a esta concepção de paisagem espelho da civilização. Quais os países além das Ilhas Britânicas, os Países Baixos, a Bélgica, parte da Alemanha Ocidental,a França e o norte da Península Ibérica que podem oferecer maior variedade de traços físicos? Não se trata de delinear de novo aqui a história geológica desta Europa de noroeste e oeste, mas, apesar de tudo, é necessário lembrar que toda a coluna geológica ali figura completa, desde os mais antigos dobramentos da era primária até as grandes convulsões pirenáicas e alpinas do terciário; ao lado das grandes bacias sedimentares do secundário e do terciário levantam-se ainda maciços vulcânicos e a glaciação quaternária contribuiu também para o modelado da fisionomia desta Europa Ocidental. Não tenho igualmente a intenção de refazer toda a descrição do clima ou melhor, dos climas. Podeis bem supor que, entre a ponta da Bretanha e o vale do Reno alsaciano, distância ridiculamente pequena para meus ouvintes acostumados às dimensões colossais do continente americano, sucedem-se nuanças muito sensíveis de clima: clima bretão com sua chuva fina, clima parisiense com seus dias luminosos de fevereiro, o duro clima loreno, o clima montanhês dos Vosges e enfim, clima alsaciano que permite a cultura da vinha e do lúpulo. Esta minúscula parte de nosso planeta apresenta um mosaico de regiões naturais e poder-se-ia pensar que ela se manifesta por igual variedade de paisagens.

A realidade é completamente diversa: encontram-se temas idênticos em qualquer rocha e qualquer clima. Desbaratando as concepções antiquadas da velha geografia, o mesmo tipo de habitat apresenta-se tanto nos terrenos impermeáveis como nos solos permeáveis. Melhor informados que seus predecessores, historiadores e geógrafos de 1939 chegam facilmente a acordo para demonstrar que os homens criaram tipos de paisagens culturais, reflexos de civilizações diferentes. Desejaria descrever rapidamente os grandes tipos de paisagens culturais da Europa Ocidental.

Antes de mais nada, as terras baixas da Holanda, da Flandres belga ou francesa, paisagens caras a esses pintores dos quais falei há pouco, são o fruto da técnica: diques que limitam as águas do Reno ou do Mosa, polders conquistados ao mar, turfeiras postas a seco, nada disto é natural. E é na luta contra o elemento aquático que os homens manifestam mais nitidamente sua capacidade de agente geográfico, criador da paisagem.

Há coisa melhor ainda, mas mais delicada para expor: as velhas canções medievais de gesta falam muitas vezes dos homens das planícies e dos homens do boca$g e$, associando às vezes, opondo-se outras. Ora, se se compreende bem o que são os homens das planícies, quais os do bocage? Que é o bocage? A geografia da paisagem pode esclarecer porque os poetas da Idade Média apenas registravam a existência desses dois tipos de sociedades rurais, tendo cada uma como domínio geográfico uma paisagem claramente caracterizada. São os dois tipos de paisagem rural que se opõem na França, por exemplo: de um lado, as das zonas de este e do 
norte, de outro as do oeste e de sul. Na Lorena ou nas planuras franco-belgas, o olhar menos prático não pode deixar de notar a forma alongada dos campos, estreitas tiras de bordas retilíneas e as cores das diversas culturas que as distinguem umas das outras; nestas campanhas, nenhuma ou poucas casas isoladas, mas, ao contrário, grandes aldeias aglomeradas. Não creiam que tal modo de povoamento corresponda a um traço físico, à permeabilidade do solo, por exemplo; descobre-se tanto nas colinas calcáreas do Artois como nos planaltos da Beauce ou nos aluviões encharcados da planície renana ou das margens do Marne. Esta paisagem não tem limites naturais, é a exteriorização de uma civilização rural, cuja antiguidade nos é comprovada pelos arqueólogos: é o reflexo da sociedade rural de costumes comunitários que Tácito descrevia entre os germanos mas cuja área ultrapassa de muito os territórios ocupados por eles ${ }^{1}$. Nas regiões onde se encontra essa paisagem sem árvores, sem cercas ao redor das propriedades rurais, sem casas esparsas, os métodos agrícolas, antes da revolução industrial moderna, eram todos inspirados nos costumes coletivos e levavam à técnica conhecida pelo nome de cultura rotativa trienal$^{2}$. Isto significa que o território pertencente à coletividade rural era dividido em três partes chamadas soles em francês, sendo cada uma delas cultivada diferente e alternativamente: é a rotação das culturas abrangendo um lapso de três anos. $\mathrm{O}$ que complica as coisas é que cada membro da coletividade rural possuía um pedaço de terra em cada sole e, o mais das vezes, diferentes bocados situados nas várias partes de cada sole. O sistema era eminentemente igualitário e democrático. Cercar cada minúscula porção faria perder superfícies respeitáveis; deixar nelas em liberdade os animais, correria o risco de prejudicar os vizinhos. A cerca era portanto interdita e da mesma forma proibida a pastagem individual. Havia somente o rebanho coletivo, que depois das colheitas, circulava livremente no território comunal, inteiramente despojado de vegetação ou de limites individuais ${ }^{3}$. O agrupamento das casas no centro deste território torna-se assim perfeitamente compreensível. E, como sociólogos e juristas nos ensinam que as sociedades que praticam esta técnica agrária definida têm costumes e instituições jurídicas e políticas comunitárias, podemos na verdade dizer que a paisagem é o reflexo de uma civilização.

Quanto ao outro tipo de paisagem, a do sul do Loire, da Normandia ou da Bretanha, seus elementos são diametralmente opostos aos do primeiro tipo. $\mathrm{O}$ bocage nada mais é que região de bosques; nada de campos de formas geométricas

\footnotetext{
1 "Agri por numero cultorum ab universis in vices occupantur, quos mos inter se secondum dignationem partiuntur... Arva per annos mutuante, et superest ager”, Tácito, Germânia, XXVI. Ver o livro de Dion: Essai sur la formation du paysage rural français. Tours, 1934, Arrault e Cia. Editores. Esta parte da conferência teve o auxílio de numerosas projeções, infelizmente impossíveis de serem reproduzidas. $\mathrm{O}$ texto deveria ser simples cometário das fotografias, planos e paisagens.

${ }^{2}$ Em geral, a rotação da cultura é feita da seguinte maneira: $1^{\circ}$. ano - trigo de inverno; $2^{\circ}$ ano cereais de primavera; $3^{\circ}$ ano - descanso.

${ }^{3} \mathrm{O}$ uso das pastagens livres através de todo o território era conhecido na França sob o nome de vaine pâture.
} 
mas, ao contrário, sebes de árvores e de arbustos que cercam a pequena propriedade perfeitamente individualizada; nada de grandes estradas que cortam os campos despidos, mas pequenos caminhos tortuosos ladeados de espessa vegetação; ao abrigo das cercas que retalham a paisagem escondem-se casas isoladas. A comunidade desaparece, deixando o lugar à propriedade individual assim como os costumes coletivos e orais cedem lugar ao direito escrito.

Esta paisagem de bocage é facilmente identificada: é a dos campos ingleses com seus cotages, estes campos que, segundo a feliz expressão do grande escritor checo Karel Capek, assemelha-se a um jardim inglês. Isto é verdade hoje, mas não o foi sempre; a história rural inglesa testemunha a transformação da paisagem a par da evolução social. Graças à fotografia aérea a serviço da arqueologia, pôde ser feita nos últimos anos curiosa descoberta: a existência, na Inglaterra, como em muitos outros lugares, na Síria, por exemplo, sobre os antigos limes romanos, de detalhes impossíveis de se distinguirem na superfície, de jazidas arqueológicas e até de formas de terrenos invisíveis ao nível do chão ${ }^{4}$. E viu-se aparecer nas chapas fotográficas, embaixo da paisagem visível e clássica, as sobrevivências de uma paisagem inglesa pré-histórica: longos traços paralelos que isolam tiras estreitas e compridas, de contornos regulares, paisagem análoga à de este da França, que os ingleses denominam openfield, expressão perfeitamente inteligível para ouvintes brasileiros que distinguem o cerrado do campo limpo ou aberto. Esta paisagem de openfield não é somente pré-histórica, mas também histórica, porque durou até a revolução industrial inglesa. No século XVI, entretanto, e de novo e com mais força ainda no século XVIII, a comunidade agrária inglesa rompeu-se; os camponeses livres, os yeomen que haviam feito a Magna Carta, partiram para a cidade; venderam suas terras ao nobres e aos industriais desejosos de possuir chão; estes destinaram a maior parte de seus domínios à criação e à caça à raposa, que exige mão de obra menos numerosa do que a cultura tradicional de cereais e sobretudo de trigo. Cercaram suas terras para que os rebanhos não se extraviassem, para que os ladrões de caça não penetrassem nelas. A paisagem de openfield transformou-se em paisagem de enclosure, de cercas, a da Inglaterra moderna. Dois períodos da história do povo inglês, dois tipos de paisagem culturais.

O título desta conferência parece-me assim amplamente justificado ${ }^{5}$; suponho, entretanto, algumas objeções no espírito dos ouvintes: os exemplos escolhidos só têm valor para os países de onde foram tomados e é evidente que nessa Europa

\footnotetext{
${ }^{4}$ Encontrar-se-á documentação extraordinariamente rica, com novos pontos de vista sobre a origem préhistórica das paisagens rurais no Tratado de Arqueologia Galo-Romana, de Grenier. Ler também o artigo de Aufrére: Lês systèmes agraires das lês Íles Britanniques. Analles de Geographie, 1935, p. 305-409.

${ }^{5}$ A justificação seria ainda mais fácil se se comparasse uma paisagem rural do norte da França em 1840 com o que ela se tornou em 1939: a perfuração de minas de carvão, o desenvolvimento das vias de comunicação rodoviárias, ferroviárias, fluviais, a invasão dos campos pelas casas dos mineiros, metamorfosearam completamente a paisagem, que, de rural, passou a ser industrial. A região do Ruhr oferece ainda exemplo mais característico.
} 
Ocidental onde desde milênios são elevadas as densidades humanas, os homens tiveram tempo para modelar a natureza e criar paisagens de civilização. Mas nas regiões onde as civilizações conservaram-se primitivas e o povoamento frágil, ou ainda nos países novos, nos quais a vitória dos homens sobre a natureza data de ontem, de hoje mesmo, em um novo como o Brasil, não poderia dar-se o mesmo?

É para responder a essas dúvidas que desejaria terminar tomando exemplos brasileiros. Vejamos primeiramente a ação das civilizações primitivas sobre a paisagem.

Sem dúvida, ninguém ignora no Brasil a existência de duas plantas muito modestas e muito familiares, largamente disseminadas nos Estados do centro e do sul, de importância capital na vida das populações do interior, mas cuja história é curiosa: o sapê, tão intimamente ligado à casa do caboclo, e o capim gordura, companheiro inseparável do zebu e da riqueza dos campos. Ora, os trabalhos dos botânicos nos ensinaram que as duas plantas haviam tido destinos análogos, se bem que fossem geograficamente diferentes. O sapê parece ser planta indígena, originário da América do Sul, provavelmente do Brasil, cuja difusão foi prodigiosa; é encontrado nas Filipinas, na Ásia das monções e na África. Partindo do Brasil, fez a volta dos trópicos. Quanto ao capim gordura, suas viagens são também surpreendentes; os botânicos fazem-no africano; é a planta sudanesa que invade os espaços conquistados à floresta pelo fogo, processo agrícola comum às sociedades rurais primitivas; encontra-se na Ásia, na América do Sul, onde os criadores argentinos e brasileiros o acreditam de boa vontade nacional. Ora, é impossível-que a disseminação dessas duas espécies seja de origem natural. Suas sementes não são daquelas que as águas e os pássaros transportam e disseminam; somente a intervenção humana, inconsciente, sem dúvida, deve ser responsabilizada pelas migrações do sapê e do capim gordura. Pode-se conceber, entretanto que migrações de tal amplitude sejam posteriores à descoberta da América? As casas da Insulíndia eram cobertas de sapê bem antes das expedições portuguesas. É-se levado a acreditar nas hipóteses etnográficas sobre povoamento americano anterior a 1492. E duas plantas características das paisagens tropicais, especialmente do Brasil, teriam sido difundidas por sociedades bem modestas... ${ }^{6}$. Os campos naturais de Mato Grosso nada têm talvez de naturais e um dos seus componentes florísticos essenciais não é, de certo, originário dali.

Mais apaixonante ainda me parece ser o estudo das paisagens modeladas à nossa vista nas regiões novas, nas zonas pioneiras. Em duas viagens efetuadas com um ano apenas de intervalo, podem-se verificar os progressos de uma paisagem: monta-se o cenário diante do geógrafo ao mesmo tempo que se cria uma sociedade, formam-se diante do sociólogo os atores que vão representar nesse cenário feito por eles mesmos. Relembramos rapidamente o que foram as paisagens paulis-

\footnotetext{
${ }^{6}$ Devem-se preciosas contribuições à história das plantas tropicais a Aug. Chevalier; ver a Revue de Botanique Appliquée et d'Agriculture Tropicale. Saint-Hilaire foi um dos primeiros a chamar a atenção sobre as consequiências do sistema da queimada sobre a evolução dos solos e da vegetação.
} 
tas: escoou-se apenas um século desde que viajantes como Saint-Hilaire ou D’Orbigny viam na província de São Paulo apenas uma terra de criação, afirmação que nos dá o direito de deduzir que, no interior, as paisagens naturais conservavam-se mais ou menos intactas: a floresta mantinha-se inviolada e, sobre as terras mais arenosas e esbranquiçadas, criavam-se os rebanhos; em alguns raros centros, como Itu e a zona litorânea, pequenas culturas de cana penetraram mais o domínio florestal. Nos trinta e cinco últimos anos do século XIX as paisagens modificaramse sensivelmente: o movimento começou pela invasão do café no vale do Paraíba, proveniente da região fluminense; de bananal a Taubaté, Zaluar admirava belas fazendas muito aristocráticas à beira da estrada do Rio das quais subsistem algumas ainda, com suas ruínas de senzalas, e as plantações de café trepavam pelas encostas da serra. Mais nítida ainda, esboçava-se e mesmo triunfava nos primeiros anos do século XX a paisagem paulista que depressa se popularizou: o oceano de café. Era o tempo do formidável rush do café, quando se plantava em todos os solos, bons e maus, sem cuidar da adaptação geográfica da cultura: as primeiras colheitas nos solos virgens eram sempre abundantes e os preços elevados para que não houvesse necessidade de selecionar com cautela as verdadeiras terras de café. Na fazenda clássica tudo se agrupava à vista do dono: a sede era sempre cuidadosamente localizada em ponto elevado para abranger-se o conjunto das instalações: terreiros e máquinas de beneficiar, ao mesmo tempo que as longas e tristes filas das colônias. A plantação de café tal como nos descreve Pierre Denis em seu Brasil no Século XX, tal como existe ainda, é um vasto domínio diante do qual o historiador não pode deixar de pensar nos domínios feudais. Tal paisagem exprime portanto uma estrutura social caracterizada e uma economia ainda colonial em muitos de seus traços.

Em 1939 a paisagem paulista sofreu transformação completa. Seria suficiente para convencer-se disto, percorrer uma destas gloriosas e vastas fazendas abertas nas imediações de Ribeirão Preto na época heróica: o cafezal já não se estende uniformemente em todos os solos; seus detritos cobrem a terra nos lugares onde ela não lhe dá rendimentos suficientes para equilibrar o preço de produção, refugia-se na verdadeira terra roxa e o restante da propriedade passa para o algodão, à laranja, à mandioca, ao arroz e à criação. Uma paisagem fragmentada, mas mais adaptada às condições geográficas, substitui-se às extensões uniformemente plantadas dos anos 1890-1900. Não somente a paisagem se anima pelos coloridos variados das diversas culturas, como se povoa pela divisão da grande fazenda: os pequenos proprietários ou mesmo os meeiros que tomam o lugar do antigo fazendeiro, vencido pelas crises econômicas, quebram o velho molde da colônia; cada um vai viver em sua própria terra, a colônia cai em ruínas e nas pequenas casas isoladas, novo tipo de habitat, surge em cada lote.Nas zonas novas da Noroeste ou de Marília, encontram-se lado a lado a fazenda tradicional com seu cafezal e as casas isoladas dos colonos japoneses, construídas a meia-encosta, acompanhando a curva de nível. Coexistência de dois tipos de habitat, de duas estruturas sociais que se con- 
cretizam na paisagem. Por vezes, ao contrário, o viajante descobre índices de recuo da pequena propriedade: minúsculos terreiros de chão batido invadidos por ervas daninhas, casas de pau a pique em ruínas, pomares sufocados pela capoeira e gado que pasta em cafezal abandonado. Extraordinária variedade atual das paisagens paulistas, que bem pouco corresponde o que esperava o europeu, à fé de narrativas já velhas de 25 anos, mas que é o reflexo das profundas e surdas revoluções agrárias. Duas épocas da história paulista, dois tipos de paisagens paulistas.

Ver como a paisagem é o reflexo da civilização, tal é uma das principais tarefas do geógrafo; é um trabalho de análise que ele precisa fazer para distinguir o que provém do solo, do clima e tambvém da técnica agrícola, da organização social. A análise da paisagem apresenta-se como o jogo de quebra-cabeça; mas, enquanto o jogo se torna logo fastidioso, é apaixonante o estudo da paisagem: apaixonante porque nos põe em contato com a humilde tarefa quotidiana e milenar das sociedades humanas; ela mostra o homem lutando sem cessar para aperfeiçoar-se. E no momento preciso em que nos sentiríamos inclinados ao desespero, dá coragem e confiança nos destinos da humanidade. 